\title{
A Combined Plan Graph and Massing Grammar Approach to Frank Lloyd Wright's Prairie Architecture
}

\author{
Ju Hyun Lee ${ }^{1} \cdot$ Michael J. Ostwald ${ }^{1} \cdot \operatorname{Ning} G_{u^{2}}$
}

\begin{abstract}
In 1981 Koning and Eizenberg famously developed a shape grammar for Wright's Prairie architecture that appeared capable of capturing its complex formal properties. However, since then, multiple researchers have argued that the underlying social and functional properties of Wright's architecture-which were excluded from Koning's and Eizenberg's analysis - are actually more significant. This paper revisits Wright's Prairie architecture using a computational and mathematical approach to examine both grammatical and syntactical aspects of the style. Through this analysis the paper identifies dominant patterns in Wright's design strategies and a design permutation which most closely captures its linguistic characteristics. A significant part in this process is that it considers both the formal and functional properties of Wright's architecture. To do this, the paper expands an existing computational method (JPG Grammar) to include a new component, a massing grammar.
\end{abstract}

\section{Introduction}

The Prairie Style developed in the midwestern United States of America in the early years of the twentieth century. It was inspired by the flat, expansive landscape of the region, leading to the design of a series of houses which feature strong horizontal

Ju Hyun Lee

Juhyun.Lee@newcastle.edu.au

Michael J. Ostwald

Michael.Ostwald@newcastle.edu.au

Ning Gu

Ning.Gu@unisa.edu.au

1 School of Architecture and Built Environment, The University of Newcastle, University Drive, Callaghan, NSW 2308, Australia

2 School of Art, Architecture and Design, University of South Australia, City West Campus, Adelaide, SA 5001, Australia 
lines and low-pitched roofs with wide, overhanging eaves (Lind 1994). Unlike the houses of the preceding era, the Prairie Style designs typically feature cruciform or T-shaped plans with social spaces on the ground floor and a smaller upper level containing bedrooms and bathrooms (Chan 1992; Amini Behbahani et al. 2016). The general principles of the Prairie Style were first formulated by Frank Lloyd Wright in a 1901 article in the Ladies Home Journal, and he remains the most famous of its proponents.

Historians describe the Prairie Style as featuring complex overlapping formal compositions in both planning and massing, which make it both distinctive and difficult to analyse (Lind 1994). However, these same properties have repeatedly drawn architectural scholars to attempt to uncover its underlying rules and properties. For example, computational and mathematical studies of Wright's Prairie houses have examined two-dimensional formal patterns (Laseau and Tice 1992), aesthetic complexity (Ostwald et al. 2010; Ostwald and Vaughan 2016), social properties (Amini Behbahani et al. 2016) and experiential characteristics (Ostwald and Dawes 2013). However, probably the most famous computational study of the Prairie houses is the shape grammar analysis of Koning and Eizenberg (1981). Their research demonstrates a set of underlying geometrical rules that appear to describe the major formal properties of Wright's Prairie houses. Furthermore, they demonstrate that it is possible to generate new Prairie Style forms using these rules. However, subsequent research argues that the formal properties of the Prairie houses are less significant than their socio-functional properties (Chan 1992; Pinnell 2005). This claim is the catalyst for the present paper, which uses a computational method to analyse the combined grammatical (rule or form-based) and syntactical (social or function-based) language of Wright's Prairie architecture. The particular method is the Justified Plan Graph Grammar (JPGG), an approach that systematically captures aspects of the two-dimensional socio-functional structure of an architectural style (Lee et al. 2015a, b; Lee 2016). However, in order to include the third dimension in this process, the approach is expanded with a new addition, a massing grammar.

The paper commences with an overview of the approach taken to investigate the Prairie houses. It then describes a generic version of the method (g-JPGG), followed by a specific variation (s-JPGG) for the testing of Wright's architecture. The s-JPGG involves the analysis of nineteen of Wright's Prairie designs, spanning from the 1902 Little House to the 1912 Adams House. The data developed from this analysis is then used to identify the dominant rules and their sequential application, used to create the underlying socio-functional properties of the houses. Thereafter, the massing grammar is briefly introduced and used to derive a three dimensional formal expression from the s-JPGG. The paper concludes by identifying the most dominant or characteristic JPGG of the Prairie houses and its formal massing. 


\section{Overview of the Method}

The two best-known approaches to computational analysis in architecture are concerned with the 'syntax' of space and the 'grammar' of form. The first of these is used for analysing spatial topologies and social relations, regardless of the forms that contain them (Hillier 1999; Hillier and Hanson 1984). The second highlights the use of rules to describe or generate the form of a design, but generally not its spatial or functional properties (Stiny and Gips 1972; Knight 1994; Çagdas 1996). Despite the successes of both methods singly, there are few examples of approaches that combine both spatial and formal considerations (Heitor et al. 2004; Eloy 2012; Krstic 2015). However, recent research has demonstrated a new method, the JPGG, which can systematically capture aspects of both the grammar and syntax of architecture in two dimensions (Lee et al. 2015a, b; Lee 2016). The present paper expands the JPGG approach to include a massing grammar, thereby including the third dimension in the analysis. Attempts to address three-dimensional architectural properties using shape grammars remain relatively rare and none have been connected to socio-functional properties in the past (Cui and Tang 2014; Koning and Eizenberg 1981).

The combined approach relies on three connected processes (Table 1). The first identifies the functionally defined group of spaces in a design, and defines them as nodes. The second links these nodes in a particular sequence, based on relative adjacency. The last component associates formal properties (shape) with each node. In terms of the conventional linguistic analogies used in computational design, this approach firstly defines the architectural 'vocabulary' of the style (its functional spaces), then its 'syntax' and 'grammar' (the social structure and rules which connect these functional spaces), and finally its 'sentence structure' or 'phraseology' (the way the combination of spaces and forms are arranged and expressed).

In the JPGG method, a node is typically defined as either a functional room or a set of programmatically related rooms (Amorim 1999; Lee 2016). A link represents a direct connection or relationship between two nodes. The complete set of nodes and their links are represented in a Justified Plan Graph or JPG (Ostwald 2011). The information embodied in the graph can be understood as a basic notational system of design, being akin to the 'spatial program' or 'bubble' diagrams used by architects. However, unlike the traditional graphs found in space syntax research, the graph in the JPGG has an implicit structural sequence embedded in the way its links are sequentially defined. Thus, using this method it is possible to identify three components of the structure of each plan graph: its 'head', 'local' connections and 'global' connections (Chomsky 1995; Corbett et al. 1993; Hillier and Hanson 1984; Lee 2016). Significantly, each node can also be given a corresponding shape, leading to the production of a massing model that has an underlying sequential structure and associated social properties.

In this paper, this method is applied to Wright's architecture as follows. The floor plans are first divided into nodes and links, which are justified in accordance with a set of rules (Fig. 1a-c). The geometric structure of each plan is considered-what Laseau and Tice (1992) call 'spatial weaves' in Wright's architecture (Fig. 1d) —as 


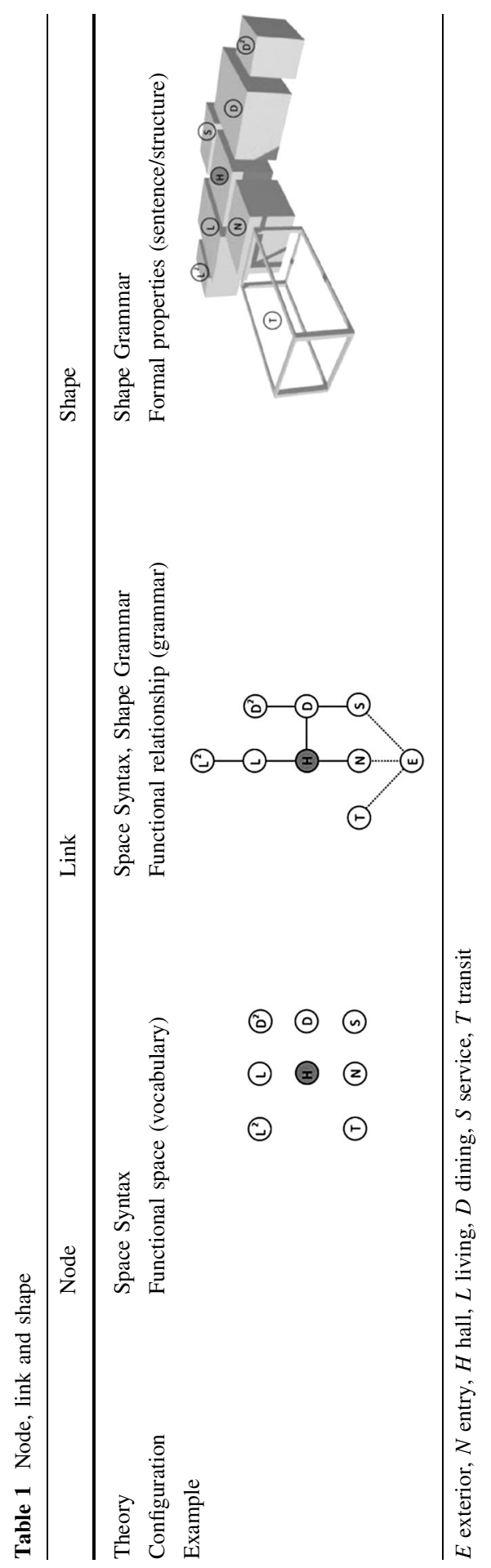



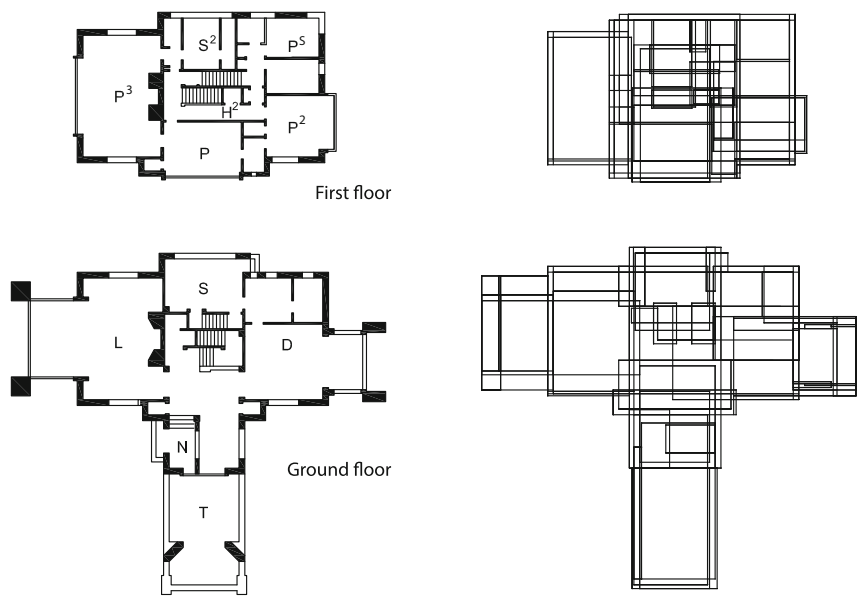

a Functional sector plan

d Spatial weaves
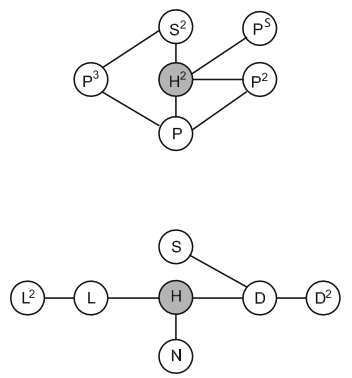

(T)

b Formal JPG

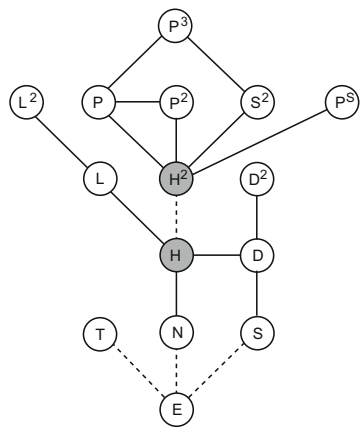

C JPG

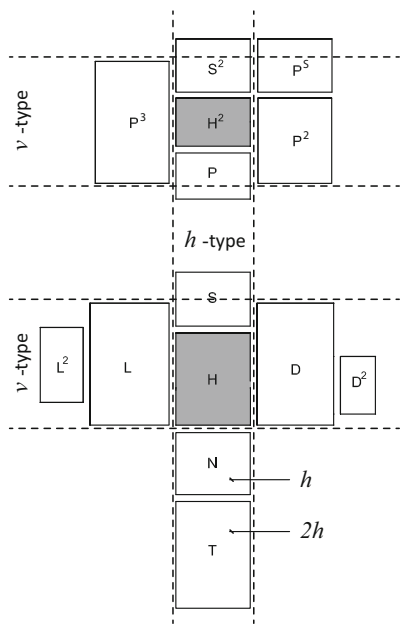

e Functional, formal modules

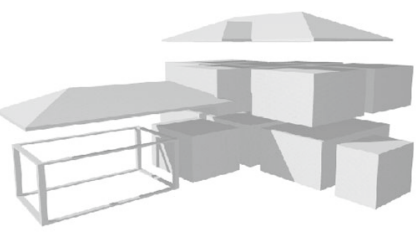

f Masssing shapes

Fig. 1 Functional, spatial, and formal analysis of the Francis W. Little House (1902), by Frank Lloyd Wright 
a precursor to identifying the formal properties of each node (Fig. 1e) and their three-dimensional expression (Fig. 1f).

\section{The g-JPGG}

A graph grammar consists of links and nodes that are used to analyse the structural and functional relations required for generating designs (Freudenstein and Maki 1979; Schmidt and Cagan 1997; Li and Schmidt 2004). The JPGG variant converts the spaces in an architectural plan into a series of sectors (nodes) that are structured (linked) in accordance with a set of rules (Lee et al. 2015a, b). The JPGG has both a generic (g-JPGG) and specific (s-JPGG) variant. In its generic form, the JPGG's spatial graph $\left(\mathrm{g}_{\mathrm{a}}\right)$ can be represented as:

$$
\mathrm{g}_{\mathrm{a}}=(N, L),
$$

where $\mathrm{N}$ is a set of nodes and $\mathrm{L}$ is a set of links represented as (i, j), with $\mathrm{i}$ and $\mathrm{j}$ nodes of the graph. Thereafter, the g-JPGG requires three stages: (1) node generation; (2) link configuration; (3) level connection (Table 2). The grammar starts with the core node generation. Since each core node usually develops the structure of the JPG, it can be regarded as the 'head' of a phrase (Chomsky 1995; Corbett et al. 1993). The first two develop local connectedness at a topological level, while the third connects different levels or storeys. Including exterior spaces defined by a building boundary in the production of the JPG, all building forms have at least two levels, the exterior and the interior topologies, which allows for 'inhabitant-visitor relations' to be examined (Dovey 1999; Ostwald 2011). The construction of the g-JPGG commences with the production of plan graphs on the ground level $\left(\mathrm{L}_{0}\right)$ and then moves on to subsequent levels $\left(\mathrm{L}_{1}, \mathrm{~L}_{2}\right.$, and so on). The eight rules for constructing a g-JPGG are presented in Table 2. Note, by applying these rules in this sequence, the resulting plan graph is given a distinct grammar, leading to the method's name. Thus, this grammar allows for two different types of social relations to be captured, by considering the relationship between the local and global syntax of the graph (Hillier and Hanson 1984).

When the JPGG has been completed for a set of designs, it captures properties of the architectural style and provides a model of the design process that has been used to develop this style.

\section{The s-JPGG}

The nineteen Prairie houses selected for analysis in this paper are all single-family houses with relatively simple plans and functional sets of rooms (Fig. 2). As such, they are typical of the majority of Wright's works produced in this style. The selection excludes designs with extensive servants' wings or outbuildings and multiple alternative social zones (such as music rooms, libraries, games rooms and conservatories). Houses with disconnected, stand-alone structures-generally garages or coach houses-are included in the set, but the external structure is 
Table 2 Generic JPG grammar

\begin{tabular}{llll}
\hline Rule set & Description & Schema & Rule diagram \\
\hline
\end{tabular}

(i) Core node generation

$L_{n} \quad R_{1} \quad$ Transform start symbol into a core node

$S_{n} \rightarrow x_{c n}$
where $x \in$
$\quad N\left(\mathrm{~L}_{n}\right)$

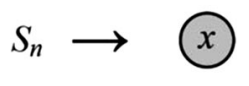

(ii) Local configuration

$L_{n} \quad R_{2} \quad$ Add node and link adjacent to a core node

$$
\begin{aligned}
& x_{c n} \rightarrow x_{c n}, y, \\
& \quad\left(x_{c n}, y\right) \\
& \text { where } x, y \in \\
& \quad N\left(\mathrm{~L}_{n}\right)
\end{aligned}
$$

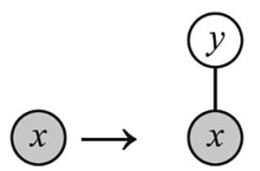

$L_{n} \quad R_{3} \quad$ Add node and link adjacent to a non-core node(s) $x \rightarrow x, y,(x$, $y)$

where $x, y \in$ $N\left(\mathrm{~L}_{n}\right)$

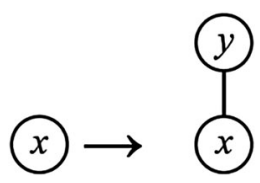

$L_{n} \quad R_{4} \quad$ Add link between non-core nodes
$x, y \rightarrow x, y$, $(x, y)$

where $x, y \in$ $N\left(\mathrm{~L}_{n}\right)$

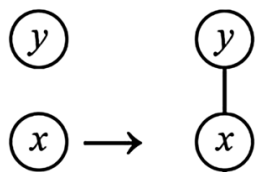

$L_{n} \quad R_{5} \quad$ Add node without a link (locally-isolated but $\quad x \rightarrow x, y$ formally-connected node in the level)
where $x, y \in$ $N\left(\mathrm{~L}_{n}\right)$
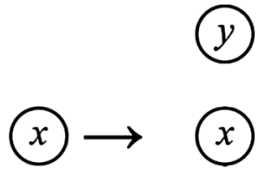

(iii) Global connection

$L_{n} \quad R_{6} \quad$ Add the exterior node and add link between a core node at the ground level and $E$

$$
\begin{gathered}
x_{c n} \rightarrow x_{c n}, E, \\
\quad\left(x_{c n}, E\right) \\
\text { where } x \in \\
\quad N\left(\mathrm{~L}_{n}\right)
\end{gathered}
$$

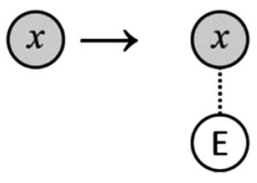

Or:

Add the exterior node and add link between a non-core node at the ground level and $E$

$$
\begin{gathered}
x \rightarrow x, E,(x, \\
E) \\
\text { where } x \in \\
\quad N\left(\mathrm{~L}_{n}\right)
\end{gathered}
$$

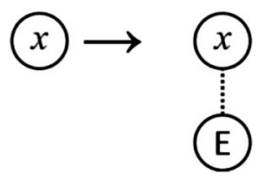


Table 2 continued

\begin{tabular}{|c|c|c|}
\hline Rule set & Description & Rule diagram \\
\hline \multirow[t]{3}{*}{$L_{n} \quad R_{7}$} & $\begin{array}{l}\text { Add link between a node(s) at the ground level } \\
\quad \text { and } E\end{array}$ & $\begin{array}{l}x, E \rightarrow x, E \\
\quad(x, E) \\
\text { where } x \in \\
\quad N\left(\mathrm{~L}_{n}\right)\end{array}$ \\
\hline & Or: & or \\
\hline & $\begin{array}{l}\text { Add link between two nodes on two different } \\
\text { topological levels, } L_{n} \text { and } L_{n-1}\end{array}$ & $\begin{array}{l}x, y \rightarrow x, y, \\
\quad(x, y) \\
\text { where } x \in \\
\quad N\left(\mathrm{~L}_{n}\right), y \in \\
\quad N\left(\mathrm{~L}_{n-1}\right)\end{array}$ \\
\hline$L_{n} \quad R_{8}$ & $\begin{array}{l}\text { If there is a further topological level to } \\
\text { configure JPGs, move to the next level }\left(L_{n+1}\right) \text {, } \\
\text { or teminate the process }\end{array}$ & Move to $L_{n+1}$ or terminaton \\
\hline
\end{tabular}

$L$ a level, $n$ the location of a level, $S$ the start symbol, $c$ a core node, $N$ a set of nodes)

excluded from the analysis. In the majority of cases, the ground floors include living and dining rooms, halls and parlours, kitchens and occasionally a maid's room. Some houses also include smaller service rooms on the ground floors (such as a pantry, laundry or bathrooms), while bedrooms and bathrooms dominate the upper levels of these designs. The plans analysed in this paper are based on Wright's final construction drawings (Futagawa and Pfeiffer 1987a, b).

For the s-JPGG, eight functional sectors are used for defining graph nodes (Table 3). If there is an additional, spatially separate or isolated grouping of each sector, it is represented by a second or third sector node. For example, some Prairie houses have three private sectors, none of which are directly connected, denoted by $\mathrm{P}, \mathrm{P}^{2}$ and $\mathrm{P}^{3}$. In addition, a private sector for servants' bedrooms is denoted as $\mathrm{P}^{\mathrm{S}}$. Some houses have only a hall $(\mathrm{H})$ as a circulation sector, while others have multiple circulation sectors including $\mathrm{N}, \mathrm{H}$ and $\mathrm{H}^{2}$.

Applying the g-JPGG procedure to each floor of the nineteen Prairie houses identifies the rules for generating each case and which are grammatically segmented according to the syntactic process (Tables 4, 5). These are an algorithmic or mathematical representation of the unique syntactic structure of Wright's Prairie architecture. By analysing the rule sets and their most frequent applications across the nineteen designs, multiple outcomes can be produced, of which the most significant, for the purposes of this paper, is identifying the dominant pattern of rules found in Wright's Prairie houses (Fig. 3).

The first rule set $\left(L_{0} R_{1}\right)$ of the s-JPGG transforms a start symbol $\left(S_{0}\right)$ into a core node at the ground level $\left(L_{0}\right)$. For the set of Wright's Prairie houses a hall sector is the core node because it is commonly located in the middle of the cruciform plan of the Prairie style, as well as serving to link to at least three sectors. These links from 

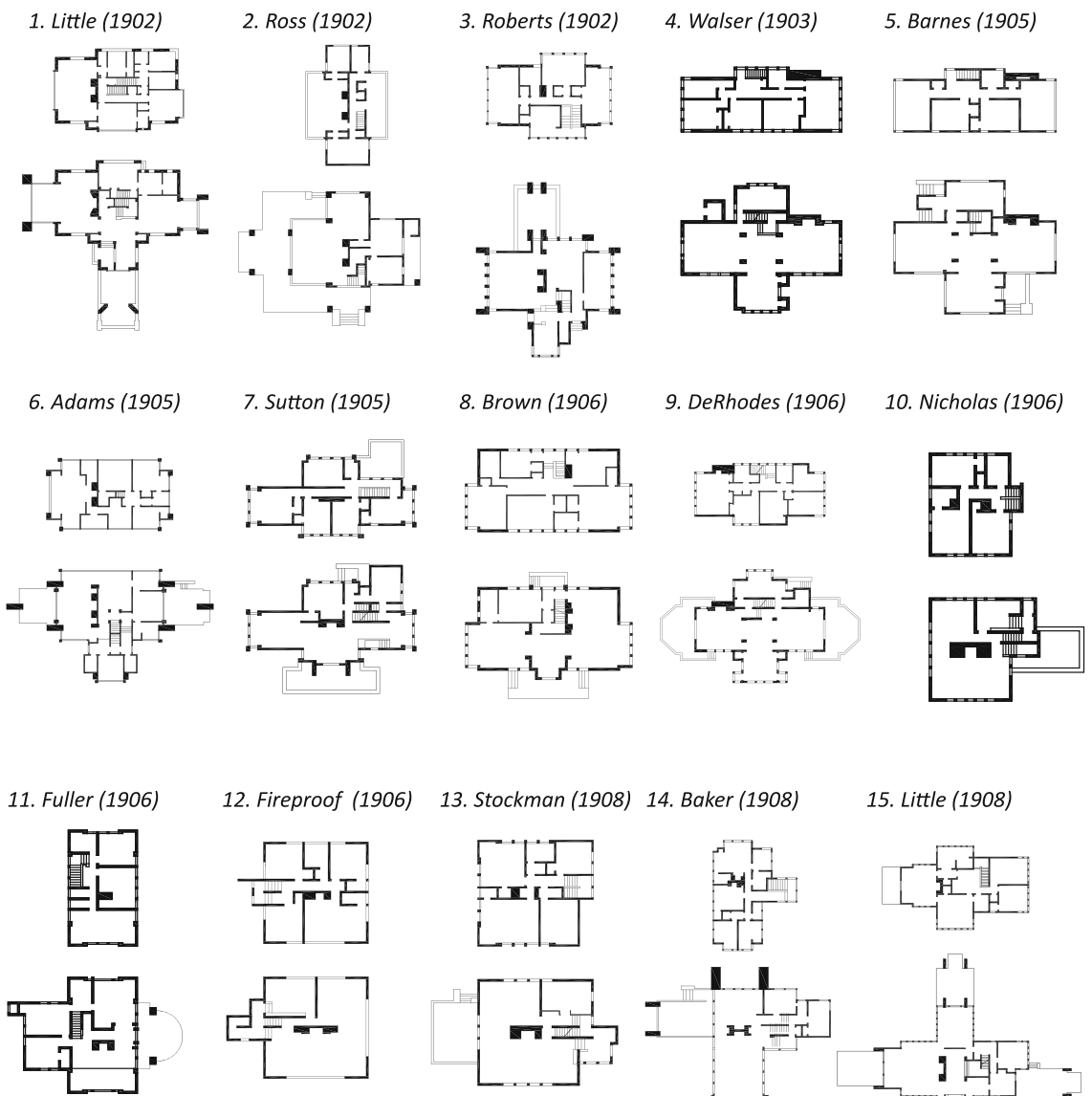

13. Stockman (1908) 14. Baker (1908)

15. Little (1908)

16. Larwill (1909)

17. Waller (1909)
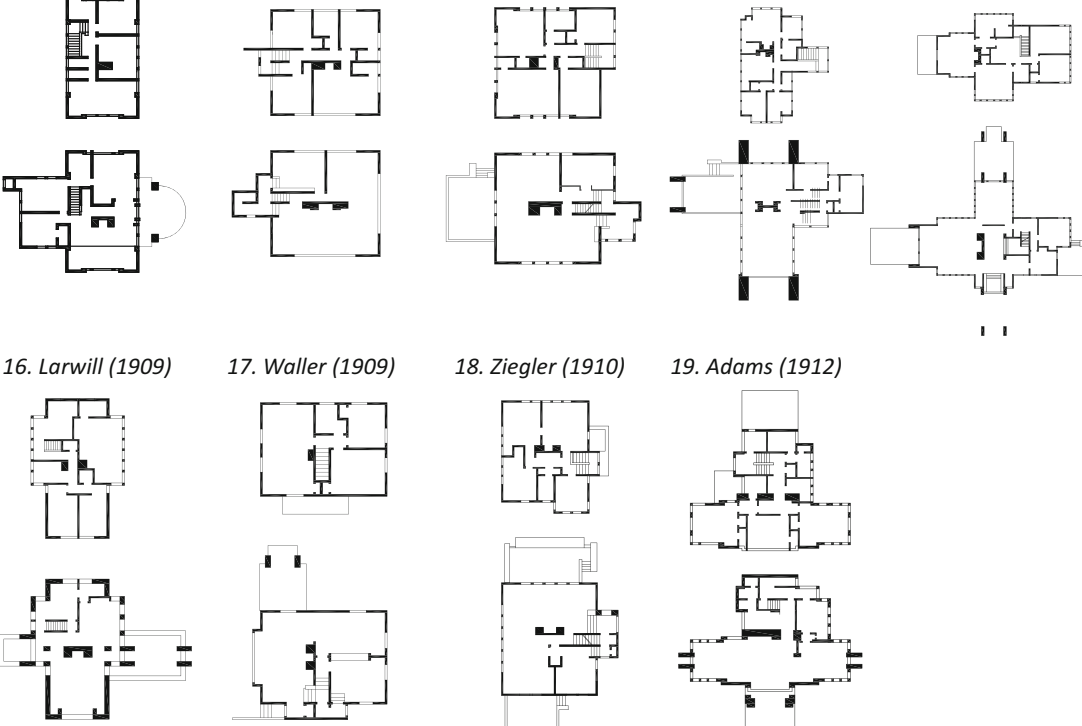

18. Ziegler (1910)

19. Adams (1912)
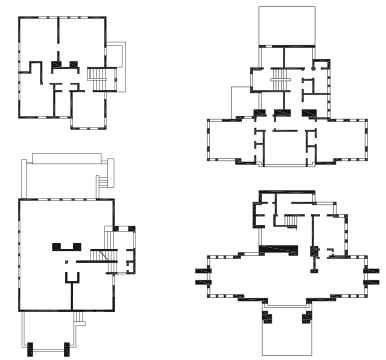

Fig. 2 Plan layouts of the nineteen Prairie houses analysed in the present study

a core node result in a syntactical head. In total, in thirteen cases a hall sector, $\mathrm{H}_{\mathrm{C} 0}$, is the core node whereas in the other six an entry sector functions as the core, $\mathrm{N}_{\mathrm{C} 0}$. Thus, for $L_{0} R_{l}$ the dominant rule is: $S_{0} \rightarrow H_{c 0}(68.4 \%)$. 
Table 3 Eight sector nodes used for the s-JPGG

\begin{tabular}{|c|c|c|}
\hline Node & Function & Description \\
\hline (E) & Exterior & Surrounding environment \\
\hline$(\mathrm{N})$ & Entry & $\begin{array}{l}\text { Functionally separates the exterior from a hall. The combination of an entry lobby and } \\
\text { a staircase is regarded as a typical entry sector }\end{array}$ \\
\hline$(\mathrm{H})$ & Hall & $\begin{array}{l}\text { Corridors, hallways, stairs and linking spaces. If a hall formally includes an entry, the } \\
\text { combination of an entry and a hall is regarded as a hall sector }\end{array}$ \\
\hline (L) & Living & Living room \\
\hline (D) & Dining & Dining room \\
\hline (S) & Service & Includes kitchens, pantries and small rooms for servants \\
\hline$(\mathrm{P})$ & Private & $\begin{array}{l}\text { Bedrooms and bathrooms. If bathrooms are formally separated, the independent space } \\
\text { is regarded as a service sector }\end{array}$ \\
\hline$(\mathrm{T})$ & Transit & $\begin{array}{l}\text { Intermediate, roofed zones, between interior and exterior, which include verandas, } \\
\text { porches and carports }\end{array}$ \\
\hline
\end{tabular}

The second rule set $\left(L_{0} R_{2}\right)$ generates nodes and links adjacent to a core node. This is topologically significant in the grammar because it defines the syntactic head of a graph. In Wright's architecture the syntactic head develops the basic cruciform plan that consists of four main functional sectors $(\mathrm{L}, \mathrm{D}, \mathrm{S}, \mathrm{N})$ with the core node in the centre. However, the components of each head vary slightly in the nineteen cases (LDSN: 26.3\%, LDST: 26.3\%, LDS: $21.1 \%$, etc.). Thus, for $L_{0} R_{2}$ the dominant rule set is: $H_{c O} \rightarrow H_{c O}, L,\left(H_{c 0}, L\right), H_{c O} \rightarrow H_{c o}, D,\left(H_{c 0}, D\right), H_{c O} \rightarrow H_{c 0}, S$, $\left(H_{c O}, S\right), H_{c O} \rightarrow H_{c O}, N,\left(H_{c o}, N\right)(26.3 \%)$.

Rule 3 for the ground floor $\left(L_{0} R_{3}\right)$ generates nodes and a second set of links starting from a node generated by the previous rule set to the adjacent nodes at the next depth. Node and link additions from non-core nodes through $L_{0} R_{3}$ usually relate to the expansion of wings and the transit sector (including T, T and $\mathrm{T}^{3}$ ) is the dominant node in the generation by $L_{0} R_{3}(63.2 \%)$.

Rule $4\left(L_{0} R_{4}\right)$ provides links between non-core nodes at the same depth. After the last two rules, the links are locally configured to generate a JPG to represent the interior topology of each house. While this rule is skipped in six cases (31.6\%), the dominant links generated by $L_{0} R_{4}$ are $(\mathrm{L}, \mathrm{D})(21.1 \%),(\mathrm{D}, \mathrm{S})(21.1 \%)$ and $\left(\mathrm{L}^{2}, \mathrm{D}\right)$ $(15.8 \%)$, which happen four, four, and three times respectively. This finding highlights that the living, dining and service sectors are treated in a surprisingly similar manner. Before addressing the global connectedness in the JPGG, $L_{0} R_{5}$ accomodates nodes that are locally-isolated, but formally-connected on a level. Only one rule $(N \rightarrow N, T)$ is developed for the first case. The local configuration ends with the fifth rule set.

Rule $6\left(L_{0} R_{6}\right)$ adds the exterior node $(\mathrm{E})$ and a link to a core node on the ground level. Thus, the dominant set of nodes and links generated by this rule is $\mathrm{E},(\mathrm{N}, \mathrm{E})$. The second dominant set is $\mathrm{E},\left(\mathrm{N}_{\mathrm{c} 0}, \mathrm{E}\right)$ or $\mathrm{E},(\mathrm{T}, \mathrm{E})$. This would also be a general consequence of the rules of the JPGG rather than of Wright's Prairie Style. Rule 7 $\left(L_{0} R_{7}\right)$ generates links between the remaining non-core nodes on the ground level and the exterior node. For $L_{0} R_{6}$ the dominant rule is: $(\mathrm{S}, \mathrm{E})(52.6 \%)$. 


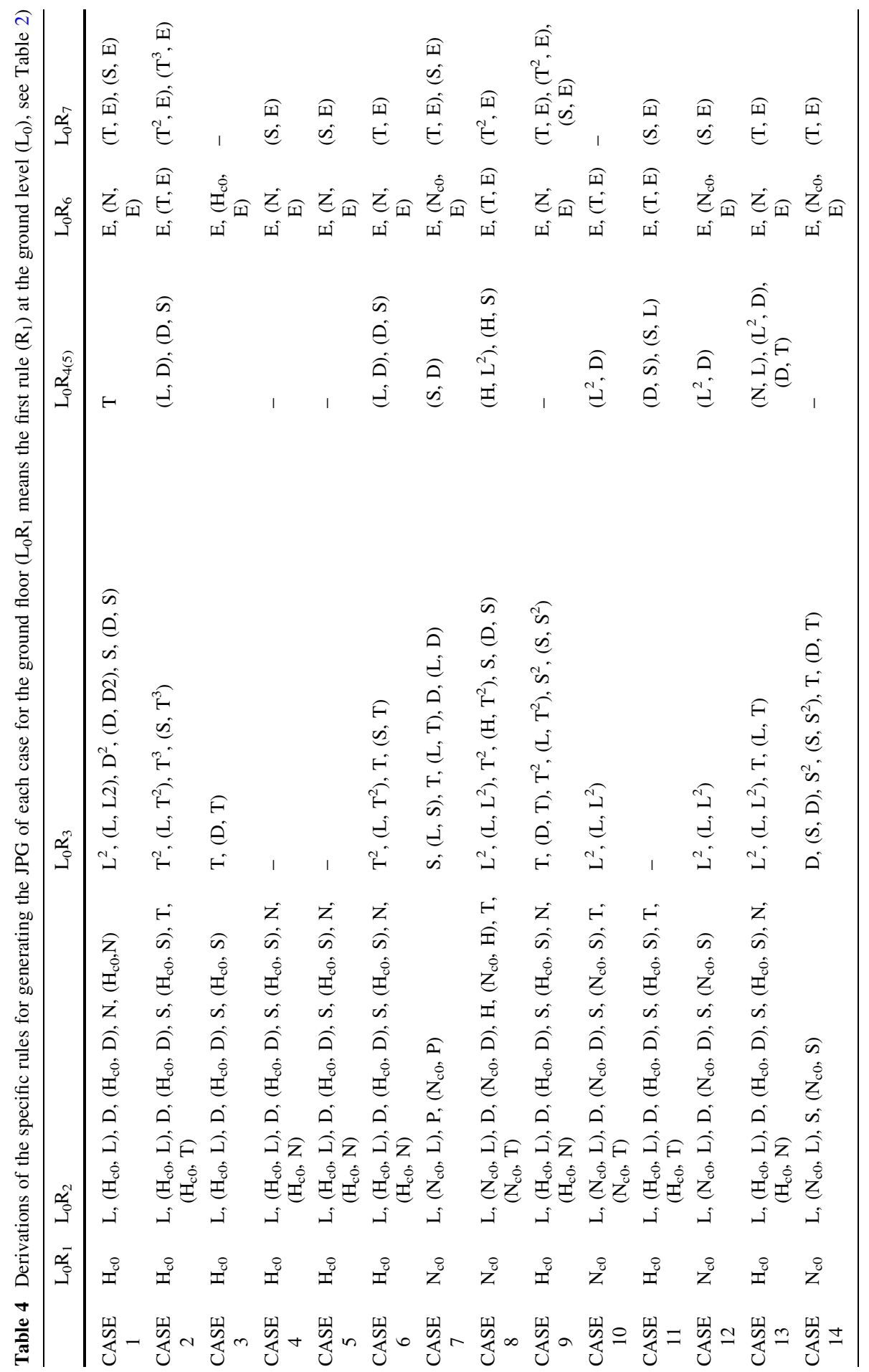




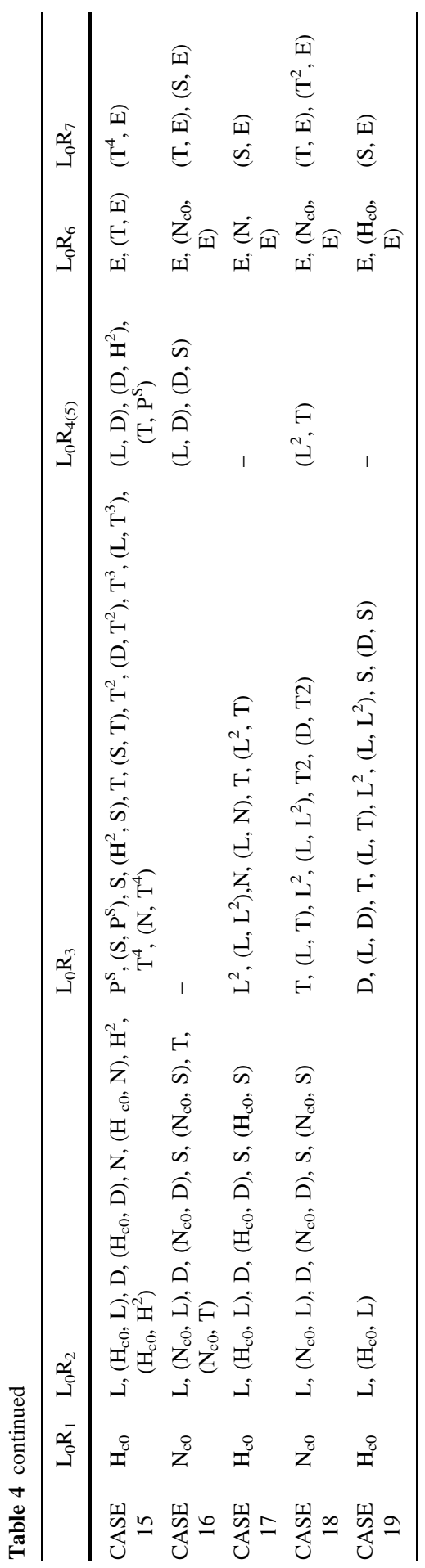




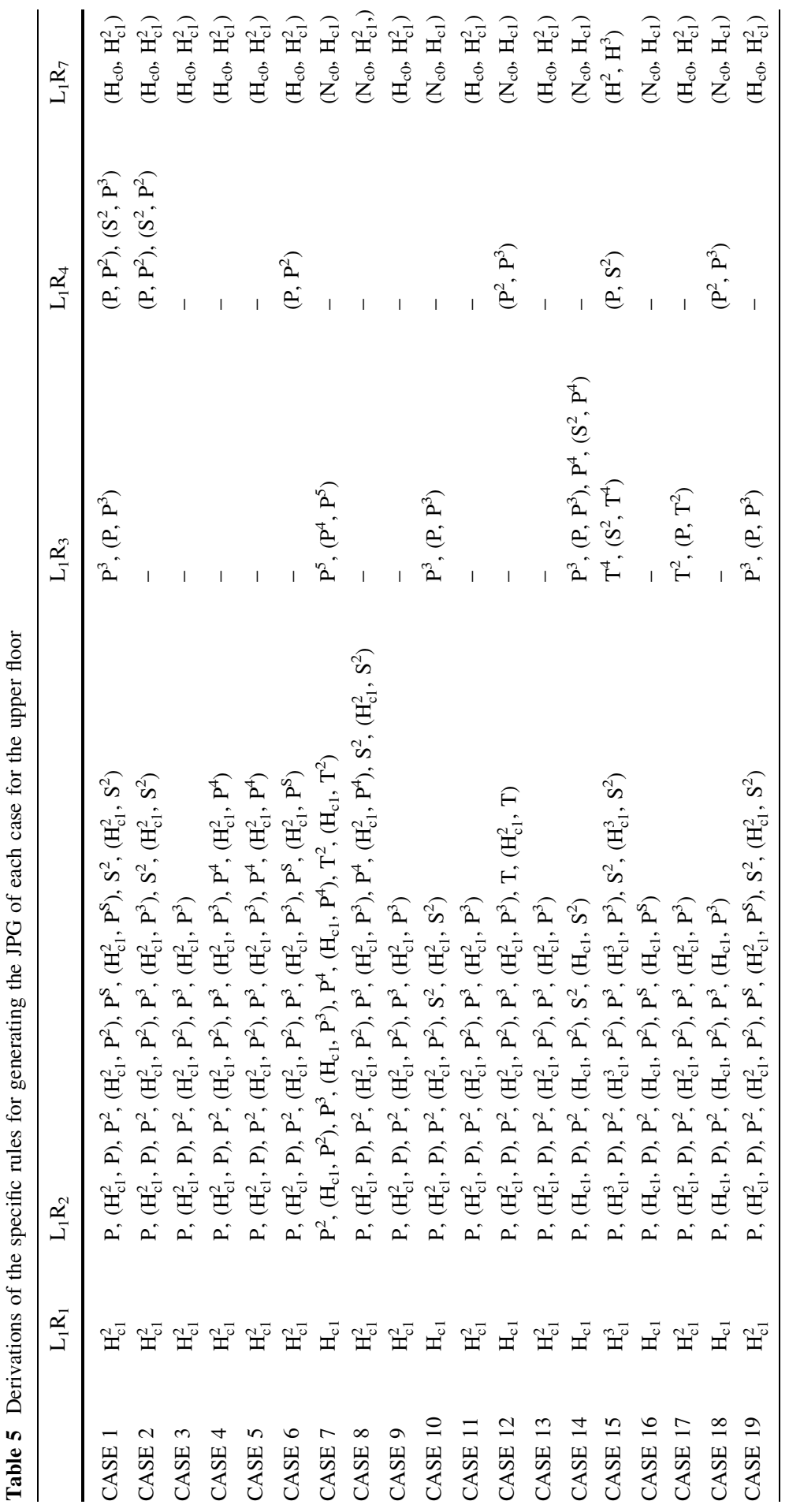




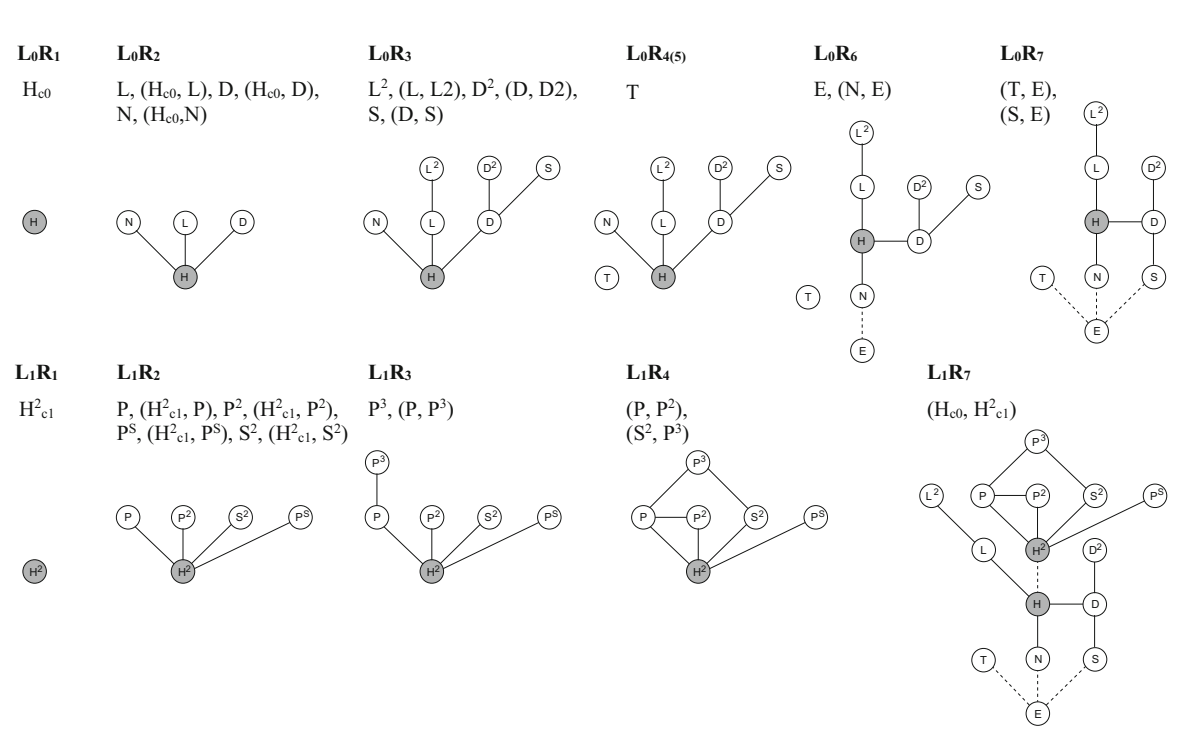

Fig. 3 JPG development of the Little House with applied rules

The same process is repeated for the upper level plan. Specifically, Rule $1\left(L_{l} R_{l}\right)$ develops a second hall sector including a staircase into a core node on the upper level $\left(L_{1}\right)$. Rule $2\left(L_{1} R_{2}\right)$ generates three private sectors $\left(\mathrm{P}, \mathrm{P}^{2}, \mathrm{P}^{3}\right)$ from the core node and then $L_{1} R_{3}$ develops either another private sector or a transit sector. After $L_{1} R_{4}$ adds links between non-core nodes, the s-JPGG finalises the local syntax of the upper floor without the application of $L_{1} R_{5}$. For the upper floor, the s-JPGG also skips the consideration of $L_{1} R_{6}$ and adds a global link between the two levels through $L_{l} R_{7}$ that is applied to the core node including a staircase on the first floor. For $L_{1} R_{1}$ the dominant rule set is: $H_{c 0}, H_{c 1}^{2} \rightarrow\left(H_{c o}, H_{c 1}^{2}\right)(57.9 \%)$. For $L_{1} R_{2}$ the dominant rule set is: $H_{c 1}^{2} \rightarrow H_{c 1}^{2}, P,\left(H_{c 1}^{2}, P\right), H_{c 1}^{2} \rightarrow H_{c 1}^{2}, P^{2},\left(H_{c 1}^{2}, P^{2}\right), H_{c 1}^{2} \rightarrow H_{c 1}^{2}$, $P^{3},\left(H_{c 1}^{2}, P^{3}\right)(26.3 \%)$. The s-JPGG skips rule for $L_{1} R_{3}$ to $L_{1} R_{6}$ and for $L_{1} R_{7}$ the dominant rule set is: $H_{c 0}, H_{c 1}^{2} \rightarrow H_{c 0}, H_{c 1}^{2}$, $\left(H_{c 0}, H_{c 1}^{2}\right)(57.9 \%)$.

The dominant rule sets in each case describe the grammar of the socio-functional properties of Wright's Prairie architecture and also identify a clear pattern in its linguistic structure. However, in order to determine the three-dimensional expression of this pattern, a further stage, the massing grammar, must be developed.

\section{Massing Grammar}

The massing grammar configures a set of shape-based extensions of the s-JPGG to illustrate the overall form of the design. This descriptive grammar involves three processes with relevant configurations for defining (a) block properties, (b) composition and (c) roof types. Because the massing grammar extends the s-JPGG, it accommodates socio-functional relationships when composing massing and thereby 
Fig. 4 Configuration of block properties of the ground floor of the Little House

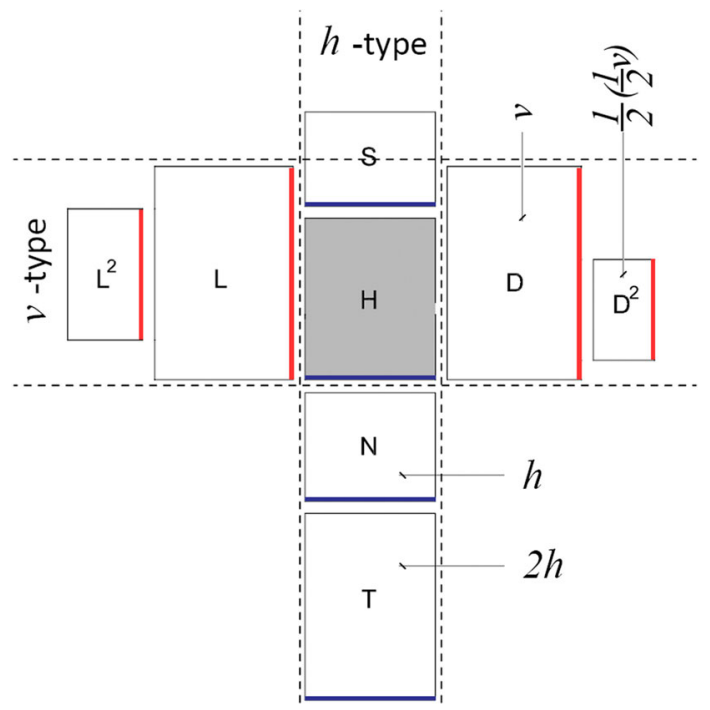

allows syntactic and topological configurations of the massing to inform analysis and generation.

In the massing grammar, any form $\left(\mathrm{SHAPE}_{\mathrm{a}}\right)$ is represented by

$\mathrm{SHAPE}_{\mathrm{a}}=$ shape $(x$, block properties, composition, roof type $)$,

where $x$ is a node. The 'block properties' consist of size, module type and material type. 'Composition' is the relationship between adjacent blocks and 'roof type' is the form of any capping to the blocks.

To start the process of producing the massing grammar, nodes in the JPG are transformed into blocks with size and orientation. Size is a multiple of the dominant planning module and there are two types of module orientation, horizontal ( $h$-type) and vertical ( $v$-type). Both module and size for this specific application of the massing grammar are in accordance with those identified in past research (Laseau and Tice 1992). Figure 4 displays the ground floor of the Little House, with nodes transformed into blocks and each annotated in accordance with the grammar. In the Little House the transit block (T) is double the normal horizontal module and is thus coded $(2 h)$. The dining block is a single vertical module $(v)$ while the nook $\left(\mathrm{D}^{2}\right)$ is a quarter of this, still vertically arrayed, $1 / 2(1 / 2 v)$. Once all of the nodes have been interpreted in this way, the three-dimensional properties can be coded.

In the third dimension, each block has a material state, a compositional relationship and a roof type. There are two material states: solid or transparent. For the Prairie houses, transparent spaces are effectively roofed but not walled. Thus, the porch of the Little House is roofed and visually defined by columns at the edges, but it is open to the weather on three sides. For this reason it is classed as transparent. All of the rest of the spaces in the Little House are enclosed with small, glazed openings, and their massing expression is therefore classified as solid. 
Fig. 5 Configuration of massing properties of the ground floor of the Little House

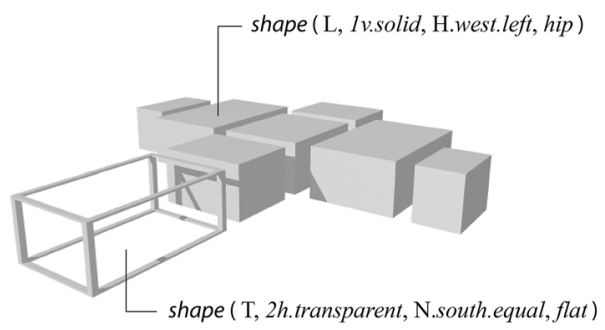

The compositional relationship describes the direction and alignment from the adjacent node. The composition thus configures spatial relationships between two nodes. Since the functional and formal modules topologically 'touch' each other (not overlap or disjoint), the massing grammar only configures the direction and alignment. There are eight symbolic directions; $D=\{$ east, west, north, south, northeast, northwest, southeast, southwest $\}$. The grammar also distingushes five types of alignment relationships: equal, centre, left, right and interleaving. The interleaving alignment refers to the diagonal relationship between nodes.

The composition connects block shapes into overall massing relationships. The connection logic is derived from the JPGG. The JPGG defines the first set of links starting from a core node (shapes) to functionally adjacent nodes (shapes) at the second depth. In a similar way, the core shape, as the first segment of the massing in the massing grammar, provides possible directions $(D)$ of the 'growth' of the massing. These configurations can be supported by the outcome of the JPG grammar because the block properties relate to the nodes and the composition deals with the links in the JPG grammar. For the Little House, the transit zone is to the south of the primary hall node $(\mathrm{N})$ and is equally aligned (Fig. 5).

Finally, the massing grammar codes roof shapes. In the case of the Prairie houses, there are only two types: hip and flat. Figure 6 illustrates the generated massing of four Prairie house examples after the final configuration. The complete massing grammar for the nineteen houses is presented in Table 6.

\section{A Statistically Ideal Prairie House}

Using the data developed from the s-JPGG and the massing grammar, it is possible to identify an architect's tendency to use a particular rule or pattern for creating socio-functional relationships and then expressing these formally. While a larger sample size would be desirable for this process, by identifying the tendancy for a rule to be applied, a dominant JPG, as a prevalent syntactic type, can be determined and then a dominant massing developed for it.

The s-JPGG identifies ' $S_{O} \rightarrow H_{c 0}$ ' as a dominant rule for the first step $\left(L_{0} R_{1}\right)$, and then develops a basic cruciform form that consists of four main functional sectors $(\mathrm{L}, \mathrm{D}, \mathrm{S}, \mathrm{N})$ in arms, with the core nodes in the centre, through the dominant rule set of $L_{0} R_{2}$, which is $H_{c O} \rightarrow H_{c 0}, L,\left(H_{c 0}, L\right), H_{c O} \rightarrow H_{c 0}, D,\left(H_{c o}, D\right), H_{c o} \rightarrow H_{c o}, S$, $\left(H_{c O}, S\right), H_{c O} \rightarrow H_{c 0}, N,\left(H_{c 0}, N\right)$. $L_{0} R_{3}$ then generates a dominant set of nodes and 
1. Little (1902)

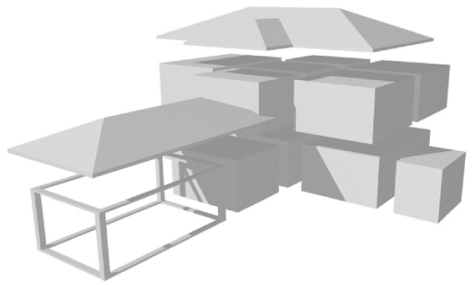

3. Roberts (1902)

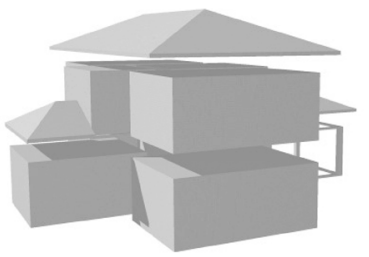

2. Ross (1902)

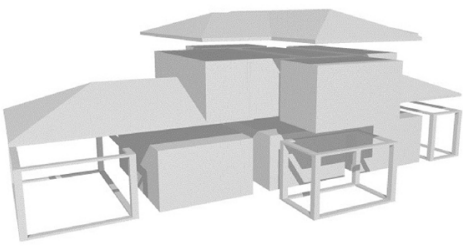

4. Walser (1903)

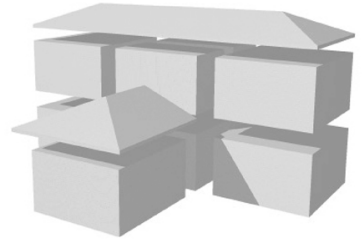

Fig. 6 Massing of four Prairie houses

links, $\mathrm{L}^{2},\left(\mathrm{~L}, \mathrm{~L}^{2}\right)$ and $\mathrm{T},(\mathrm{L}, \mathrm{T})$. In addition, the s-JPGG generates $\mathrm{S},(\mathrm{D}, \mathrm{S})$ or $\mathrm{T}^{2},(\mathrm{~L}$, $\mathrm{T}^{2}$ ) or $\mathrm{T},(\mathrm{D}, \mathrm{T})$, which is the next dominant set. This is because the grammar application commonly generates three dominant sets in this rule. $S,(D, S)$ is chosen for this application, lacking a sufficiently large enough volume of data to make a more detailed determination. Thus, $L_{0} R_{3}$ generates $\mathrm{L}^{2},\left(\mathrm{~L}, \mathrm{~L}^{2}\right), \mathrm{T},(\mathrm{L}, \mathrm{T}), \mathrm{S},(\mathrm{D}, \mathrm{S})$. $L_{0} R_{4}$ is then skipped or generates one link between the two dominant links, (L, D) and (D, S). $L_{0} R_{4}$ and $L_{0} R_{5}$ are not applied to generate this syntactic type because the skipped links are the dominant condition. $L_{0} R_{6}$ adds the exterior node, E, and a link, $(\mathrm{N}, \mathrm{E}) . L_{0} R_{7}$ can generate the most dominant link, $(\mathrm{S}, \mathrm{E})$, but if there is a transit node it develops a link between the transit node to the exterior, which is the second dominant link, (T, E). Finally, we can identify a prevalent syntactic type of JPG on the ground level through the s-JPGG, which can be represented as follows.

$$
\begin{aligned}
\mathrm{g}_{\text {dominant JPG-L0 }}= & \left\{\mathrm{H}_{\mathrm{c} 0}, \mathrm{~L}, \mathrm{D}, \mathrm{S}, \mathrm{N}, \mathrm{L}^{2}, \mathrm{~T}, \mathrm{E},\left(\mathrm{H}_{\mathrm{c} 0}, \mathrm{~L}\right),\left(\mathrm{H}_{\mathrm{c} 0}, \mathrm{D}\right),\right. \\
& \left.\left(\mathrm{H}_{\mathrm{c} 0}, \mathrm{~S}\right),\left(\mathrm{H}_{\mathrm{c} 0}, \mathrm{~N}\right),\left(\mathrm{L}, \mathrm{L}^{2}\right),(\mathrm{L}, \mathrm{T}),(\mathrm{D}, \mathrm{S}),(\mathrm{N}, \mathrm{E}),(\mathrm{T}, \mathrm{E})\right\} .
\end{aligned}
$$

This is repeated for the upper floor, where the dominant first rule set $\left(L_{1} R_{1}\right)$ develops a second hall node $\left(\mathrm{H}_{\mathrm{c} 1}^{2}\right)$ and $L_{1} R_{2}$ generates three private nodes $\left(\mathrm{P}, \mathrm{P}^{2}, \mathrm{P}^{3}\right)$. The s-JPG grammar skips the next rules until it adds a global link between the two levels through $L_{1} R_{7}$. Ultimately, through the most common rule sets applied in the given cases, the s-JPG grammar identifies a prevalent JPG.

In the same way the massing grammar rules and data can be used to identify the prevalent outcome. Based on this information, the grammar identifies three $v$-type blocks for $\mathrm{L}, \mathrm{D}, \mathrm{L}^{2}$ and four $h$-type blocks for $\mathrm{H}_{\mathrm{c} 0}, \mathrm{~S}, \mathrm{~N}, \mathrm{~T}$ on the ground floor. All blocks conform to the simplified-modular size and only the transit block has transparent walls. The hall block lies in the centre and then the other blocks are located using the data from block compositions. For example, L locates to the west 
Table 6 Derivations of the composition rules for generating massing blocks on the ground levels

Block composition

CASE 1 shape (H, 1h.solid, coreblock, shape (D, 1v.solid, H.east.right), shape (L, 1v.solid, H.west.left), shape (N, 1h.solid, H.south.equal), shape (S, 1h.solid, H.north.equal), shape (L2, 1/2(1/2v).solid, L.west.centre), shape (D2, 1/2(1/2v).solid, D.east.right), shape (T, 2h.transparent, N.south.equal)

CASE 2 shape (H, 1h.solid, coreblock), shape (S, 1v.solid, H.east.right), shape (L, 1v.solid, H.west.left), shape (T, 1/2h.transparent, H.south.equal), shape (D, 1h.solid, H.north.equal), shape (T2, 1v.transparent, L.east.centre), shape (T3, (1/2v).transparent, S.west.centre)

CASE 3 shape (H, 1h.solid, coreblock), shape (S, 1/2v.solid, H.northeast.lnterleaving), shape (L, $1 v$.solid, H.northwest.lnterleaving), shape (D, 1h.solid, H.north.equal), shape (T, 1h.transparent, D.northwest.lnterleaving)

CASE 4 shape (H, 1h.solid, coreblock), shape (L, 1v.solid, H.east.equal), shape (D, 1v.solid, H.west.equal), shape (N, 1h.solid, H.south.equal), shape (S, 1h.solid, H.north.equal)

CASE 5 shape (H, 1h.solid, coreblock), shape (L, 1v.solid, H.east.centre), shape (D, 1v.solid, H.west.centre), shape ( $N$, 1h.solid, H.south.centre), shape (S, 1h.solid, H.north.centre)

CASE 6 shape (H, 1h.solid, coreblock), shape (S, 3/4v.solid, H.east.right), shape (L, 1v.solid, H.west.left), shape (N, 1h.solid, H.south.equal), shape (D, 1h.solid, H.north.equal), shape (T, (1/2v).transparent, S.east.centre), shape (T2, (1/2v).transparent, L.west.centre)

CASE 7 shape ( $N$, 1v.solid, coreblock), shape (L, 1h.solid, N.west.right), shape (P, (1/2h).solid,

N.north.equal), shape (S, 1h.solid, L.north.equal), shape (D, 1v.solid, L.west.right), shape (T, Ih.transparent, L.south.equal)

CASE 8 shape (N, 1h.solid, coreblock), shape (T, (1/3v).transparent, N.east.equal), shape (H, 1v.solid, N.west.equal), shape (L, 4/3h.solid, N.south.equal), shape (S, 4/3h.solid, N.north.equal), shape (L2, 2v.solid, H.south.equal), shape (D, 2v.solid, H.north.equal), shape (T2, (2) $3 v)$.transparent, H.west.equal)

CASE 9 shape (H, 1h.solid, coreblock), shape (D, 1v.solid, H.east.equal), shape (L, 1v.solid, H.west.equal), shape (N, 2/3h.solid, H.south.equal), shape (S, 2/3h.solid, H.north.equal), shape (T, 1v.transparent, D.east.equal), shape (T2, 1v.transparent, L.west.equal), shape (S2, (1/2h).solid, S.east.equal)

CASE shape $(N, 1$ h.solid, coreblock), shape ( $T$, (1/2v).transparent, N.east.left), shape (D, 1v.solid, 10 N.northwest.lnterleaving), shape (L, (1/2h).solid, N.south.right), shape (S, 1h.solid, N.north.equal), shape (L2, 1v.solid, L.west.equal)

CASE shape (H, 1h.solid, coreblock), shape (T, 1v.solid, H.east.centre), shape (S, 1v.solid, 11 H.west.centre), shape (L, Ih.solid, H.south.equal), shape (D, 1h.solid, H.north.equal)

CASE shape (H, 1h.solid, coreblock), shape (D, 1v.solid, H.northeast.lnterleaving), shape (N, 1/2(1/ 12 2v).solid, H.west.equal), shape (L, 2h.solid, H.south.equal), shape (S, 2h.solid, H.north.equal), shape ( $L^{2}$, 1v.solid, L.east.equal)

CASE shape (H, 1h.solid, coreblock), shape (N, 1/2(1/2v).solid, H.southeast.lnterleaving), shape (D, 13 1v.solid, H.northwest.lnterleaving), shape (L, 2(3/4h).solid, H.south.right), shape (S, $3 / 2$ h.solid, H.north.equal), shape ( $L^{2}, 1$ v.solid, L.west.equal), shape (T, 5/2h.transparent, L2.northwest.lnterleaving)

CASE shape $(N, 1 / 2(2 / 3 v)$.solid, coreblock), shape (S, 1/2.solid, N.north.equal), shape (L, 2h.solid, 14 N.southwest.lnterleaving), shape $\left(S^{2}, 1 / 2 v\right.$.solid, S.southeast.lnterleaving), shape (D, Ih.solid, L.north.equal), shape (T, 1v).transparent, D.west.right)

CASE shape (H, lh.solid, coreblock), shape $\left(H^{2},(1 / 3 v)\right.$.solid, H.northeast.lnterleaving), shape (L, 15 Iv.solid, H.west.left), shape (N, 1/3h.solid, H.south.equal), shape (D, 1h.solid,

H.north.equal), shape $\left(S,(1 / 2 v)\right.$.solid, H2.east.left), shape $\left(P^{S},(1 / 2 v)\right.$.solid,

S.southwest.lnterleaving), shape ( $T,(1 / 2 v)$.transparent, Ps.east.equal), shape $\left(T^{2}\right.$,

1h).transparent, D.north.equal), shape $\left(T^{3}\right.$, (3/4v).transparent, L.west.centre), shape $\left(T^{4}\right.$,

1h.transparent, N.south.equal) 
Table 6 continued

Block composition

\begin{tabular}{|c|c|}
\hline $\begin{array}{l}\text { ASE } \\
16\end{array}$ & $\begin{array}{l}\text { shape (N, 1h.solid, coreblock), shape (D, 1v.solid, N.east.right), shape }(T, 1 / 2(1 / 2 v), \\
\quad \text { N.west.left), shape (L, Ih.solid, N.southeast.lnterleaving), shape ( } S \text {, 1h.solid, N.noth.equal) }\end{array}$ \\
\hline $\begin{array}{c}\text { CASE } \\
17\end{array}$ & 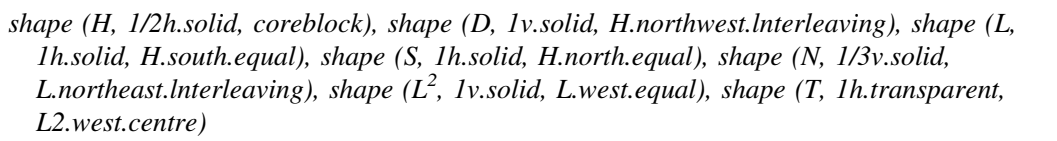 \\
\hline $\begin{array}{c}\text { CASE } \\
18\end{array}$ & 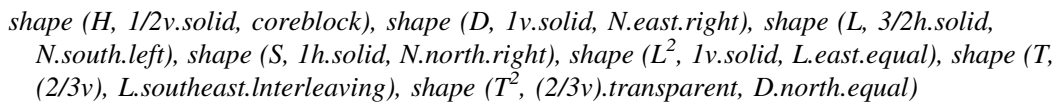 \\
\hline $\begin{array}{c}\text { CASE } \\
19\end{array}$ & $\begin{array}{l}\text { shape }(H, 1 h . s o l i d, \text { coreblock }), \text { shape }(L, 1 \text { h.solid, H.south.equal), shape }(D, 1 \text { v.solid, } \\
\text { L.east.equal }), \text { shape }\left(L^{2}, 1 \text { v.solid, L.west.equal }\right), \text { shape }(T, 1 \text {.transparent, L.south.equal), } \\
\text { shape }(S, 2 / 3 v . \text { solid, D.north.left })\end{array}$ \\
\hline
\end{tabular}

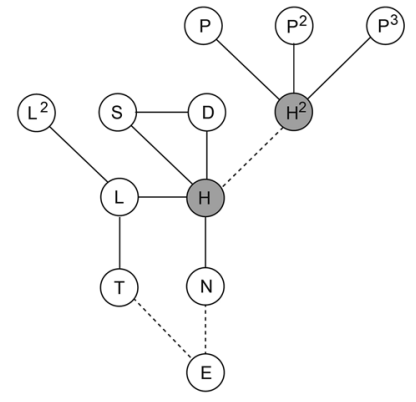

a JPG

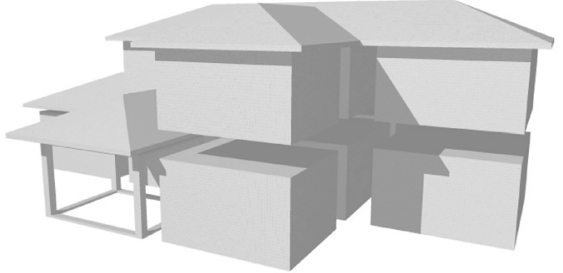

b Massing form

Fig. 7 The dominant prairie house socio-functional relationship (JPG) and formal expression (massing)

of the hall block and $\mathrm{N}$ locates to the south. Figure 7 illustrates the prevalent form generated by the combined plan graph and massing grammar approach.

\section{Conclusion}

The generation of the dominant socio-functional graph and its associated massing is effectively a statistical process, using the most frequently applied rules and sequence uncovered in the set of nineteen of Wright's houses. What is signficant about this outcome is that it is the first time that both the spatial and formal properties of the Prairie houses have been simultaneously captured and then retained through the process of generating, or identifying, what is effectively a new design. For this reason, the outcome is very different to the designs generated by Koning and Eizenberg using shape grammar alone. In this way the language of Wright's Prairie architecture is revealed to be more than just a clever manipulation of forms. Instead, it involves a close relationship between social patterns, functional zonings and their associated formal expression. 


\section{References}

Amini Behbahani, Peiman, Michael J. Ostwald and Ning Gu. 2016. A syntactical comparative analysis of the spatial properties of Prairie style and Victorian domestic architecture. The Journal of Architecture 21 (3): 348-374.

Amorim, L. M. D. E. 1999. The sectors' paradigm: a study of the spatial and functional nature of modernist housing in Northeast Brazil. Ph.D. thesis, University of London.

Çağdaş, G. 1996. A shape grammar: the language of traditional Turkish houses. Environment and Planning B: Planning and Design 23 (4): 443-464.

Chan, C.-S. 1992. Exploring individual style in design. Environment and Planning B: Planning and Design 19 (5): 503-523.

Chomsky, Noam. 1995. The Minimalist Program. Cambridge: The MIT Press.

Corbett, Greville G., Norman M. Fraser and Scott Mcglashan (Eds.). 1993. Heads in Grammatical Theory. Cambridge: Cambridge University Press.

Cui, Jia and Ming-Xi Tang. 2014. Representing 3D shape grammars in a generative product design system. In John S. Gero (Ed.), Design Computing and Cognition'12 (pp. 377-392). New York; London: Springer.

Dovey, Kim. 1999. Framing Place: Mediating Power in Built Form. London: Routledge.

Eloy, Sarah. 2012. A transformation grammar-based methodology for housing rehabilitation. Ph.D. thesis, Universidade Técnica de Lisboa.

Freudenstein, F. and E. R. Maki. 1979. The creation of mechanisms according to kinematic structure and function. Environment and Planning B 6 (4): 375-391.

Futagawa, Yukio, and Bruce Brooks Pfeiffer. 1987a. Frank Lloyd Wright Monograph 1887-1901. Vol. 1. Tokyo: A.D.A. Edita.

Futagawa, Yukio, and Bruce Brooks Pfeiffer. 1987b. Frank Lloyd Wright Monograph 1907-1913. Vol. 3. Tokyo: A.D.A. Edita.

Heitor, Teresa, José Pinto Duarte and Rafaela Marques Pinto. 2004. Combining grammars and space syntax: formulating, generating and evaluating designs. International Journal of Architectural Computing 2 (4): 492-515.

Hillier, Bill. 1999. Space is the Machine: A Configurational Theory of Architecture. Cambridge: Cambridge University Press.

Hillier, Bill and J. Hanson. 1984. The Social Logic of Space (Vol. 1). Cambridge: Cambridge University Press.

Knight, Terry. W. 1994. Transformations in Design: A Formal Approach to Stylistic Change and Innovation in the Visual Arts. Cambridge: Cambridge University Press.

Koning, Hank and Julie. Eizenberg. 1981. The language of the prairie: Frank Lloyd Wright's Prairie houses. Environment and Planning B 8 (3): 295-323.

Krstic, D. 2015. Language of the Rascian School: analyzing Rascian church plans via parallel shape grammar. In J. S. Gero and S. Hanna (Eds.), Design Computing and Cognition'14 (pp. 421-436): Springer International Publishing.

Laseau, Paul and James Tice. 1992. Frank Lloyd Wright: Between Principles and Form. New York: Van Nostrand Reinhold.

Lee, J. H., Michael J. Ostwald and Ning Gu. 2015a. A syntactical and grammatical approach to architectural configuration, analysis and generation. Architectural Science Review 58 (3): 189-204.

Lee, J. H., Michael J. Ostwald and Ning Gu. 2015b. Using a JPG Grammar to Explore the Syntax of a Style: An Application to the Architecture of Glenn Murcutt. In J. S. Gero and S. Hanna (Eds.), Design Computing and Cognition '14 (pp. 589-604). Cham: Springer International Publishing.

Lee, J. H., Michael J. Ostwald and Ning Gu. 2016. A Justified Plan Graph (JPG) grammar approach to identifying spatial design patterns in an architectural style. Environment and Planning B Planning and Design, online.

Li, Xin and Linda Schmidt. 2004. Grammar-based designer assistance tool for epicyclic gear trains. Journal of Mechanical Design 126 (5): 895-902.

Lind, Carla. 1994. Frank Lloyd Wright's Prairie houses. California: Archetype Press.

Ostwald, Michael J. 2011. A justified plan graph analysis of the early houses (1975-1982) of Glenn Murcutt. Nexus Network Journal 13 (3): 737-762.

Ostwald, Michael J., and Michael J. Dawes. 2013. Prospect-refuge patterns in Frank Lloyd Wright's Prairie houses: using isovist fields to examine the evidence. Journal of Space Syntax 4 (1):136-159. 
Ostwald, Michael J. and Josephine L. Vaughan. 2010. The mathematics of style in the architecture of Frank Lloyd Wright: A computational, fractal analysis of formal complexity in fifteen domestic designs. In Paul S Geller (Ed.), Built Environment: Design, Management and Applications. New York: Nova Scientific.

Ostwald, Michael J. and Josephine L. Vaughan. 2016. The Fractal Dimension of Architecture. Cham, Switzerland: Birkhauser.

Pinnell, Patrick. 2005. Academic tradition and the individual talent. In Robert McCarter (Ed.), On and By Frank Lloyd Wright (pp. 22-55). New York: Phaidon.

Schmidt, L. and J. Cagan. 1997. GGREADA: A graph grammar-based machine design algorithm. Research in Engineering Design 9 (4): 195-213.

Stiny, George and James Gips. 1972. Shape grammars and the generative specification of painting and sculpture. In C. V. Freiman (Ed.), Information Processing 71 (pp. 1460-1465). Amsterdam: NorthHolland.

Ju Hyun Lee is Senior Lecturer in the School of Architecture and Built Environment, at the University of Newcastle, Australia. Dr. Lee has made a significant contribution towards architectural and design research in three main areas: design cognition, planning and design analysis, and design computing. As an expert in the field of architectural and design computing, he was invited to become a visiting academic at the University of Newcastle in February 2011. His international contribution has been recognised as: Associate editor for a special edition of Architectural Science Review; Reviewer for many international journals and conferences; International reviewer for national grants.

Michael J. Ostwald is Dean of Architecture at the University of Newcastle (Australia) and a Visiting Professor at RMIT University (Australia). Michael has a PhD in architectural history and theory and a higher doctorate (DSc) in design mathematics. He is Co-Editor-in-Chief of the Nexus Network Journal: Architecture and Mathematics and a member of the editorial boards of ARQ and Architectural Theory Review. Michael's more than 300 published research papers cover aspects of the history and theory of geometry and design, and applications of computing in architectural analysis.

Ning Gu is Professor of Architecture in the School of Art, Architecture and Design at the University of South Australia. His most significant research contributions have been made in the fields of architectural and design computing. His research outcomes have been documented in over 150 peer-reviewed publications. He has been a reviewer/guest editor for major international journals in the field including Design Studies, Automation in Construction, Architectural Science Review, IJAC and ITCon. He was a visiting scholar at MIT, Columbia University and Technische Universiteit Eindhoven. 